\title{
Нелинейный режим работы ВОЛС с распределенными рамановскими усилителями
}

\author{
Д.Д. Старых ${ }^{1,2, *}$, В.А. Конышев ${ }^{1,5}$, О.Е. Наний, ${ }^{1,2,3}$, \\ В.Н Трещиков ${ }^{1,4}$, И.И. Шихалиев ${ }^{1,2}$ \\ ${ }^{1}$ Группа компаний Т8 \\ ${ }^{2}$ Московский физико-технический институт (государственный университет) \\ ${ }^{3}$ Московский государственный университет им. М.В. Ломоносова \\ ${ }^{4}$ Институт радиотехники и электроники им. В.А. Котельникова РАН \\ ${ }^{5}$ Институт истории естествознания и техники им. С.И. Вавилова РАН \\ *E-mail: starykh@phystech.edu
}

DOI:10.31868/RFL2018.212-213

Наиболее распространенным и энергоэффективным средством передачи данных на дальние расстояния с высокой скоростью является когерентная оптическая связь [1], [2]. Максимальная дальность передачи и длина отдельного пролета в когерентных волоконно-оптических линиях связи (ВОЛС) ограничена двумя основными факторами: линейными шумами спонтанной люминесценции эрбиевого усилителя (EDFA) и нелинейными эффектами в волокне . Оба явления уменьшают оптическое соотношение сигнал/шум (OSNR) на входе в приемник транспондера, что приводит к ухудшению качества оптического сигнала и, как следствие, к ошибкам при его демодуляции. OSNR в конце линии можно повысить за счет увеличения мощности сигнала, однако увеличение мощности оптического излучения в волоконном тракте приводит к появлению нелинейных эффектов, таких как фазовая самомодуляция, фазовая кросс-модуляция, четырехволновое смешение и других. Поскольку в случае когерентной системы передачи дисперсия компенсируется транспондером при цифровой обработке сигнала [3], элементы физической компенсации дисперсии можно не использовать в когерентных ВОЛС. Вследствие этого из-за большой накопленной дисперсии перечисленные выше нелинейные эффекты проявляют себя как аддитивный гауссов шум [4], [5]. Таким образом нелинейные эффекты в когерентных ВОЛС можно характеризовать мощностью нелинейного шума, которая суммируется с мощностями шумов спонтанной люминесценции эрбиевых усилителей.

Наилучшая производительность ВОЛС достигается при максимально высокой мощности на выходе линии, при которой слабо развиваются нелинейные эффекты. Этого можно добиться используя распределенные рамановские усилители. В процессе вынужденного комбинационного (ВКР) или рамановского рассеяния [6] телекоммуникационное волокно выступает в роли усиливающей среды. Таким образом увеличивается сигнальная мощность в конце пролета линии и отношение мощности сигнала к мощности шумов спонтанной люминесценции $\left(\mathrm{OSNR}_{\mathrm{L}}\right)$ на выходе линии. Но при этом усложняется задача учета нелинейных искажений. Для учета подобных искажений создана феноменологическая расчетная модель нелинейного шума в многоканальных 100G DP-QPSK BOЛC c распределенными рамановскими усилителями с попутной накачкой.

В схеме Рис. 1 были проведены эксперименты для выявления зависимостей полной мощности нелинейного шума от различных параметров продольного профиля канальной мощности Рис. 2, таких как максимум мощности исследуемого канала в линии $\left(P_{p e a k}^{\text {main }}\right)$ и воздействующих каналов $\left(P_{\text {peak }}^{n_{c h}}\right)$, 
удаленности точки, в которой достигается $P_{\text {peak }}^{\text {main }}$, от места ввода накачки $\left(\mathrm{Z}_{\text {peak }}\right)$, дисперсии на входе в линию ( $\left.D^{i n}\right)$, а также количества $\left(N_{c h}\right)$ и спектрального расположения воздействующих каналов $(\Delta f)$. Сформированная феноменологическая модель (1) - (3) позволяет рассчитывать полную мощность нелинейного шума $\left(P_{N L}^{\text {full }}\right)$ в когерентных 100G DP-QPSK ВОЛC с распределенными рамановскими усилителями с попутной накачкой мощностью до 1 Вт на длинах волн от 1425 нм до 1480 нм. Сравнение расчетного запаса по OSNR с экспериментальным показало расходимость не более 1 дБ.

$$
\begin{gathered}
P_{N L}^{\text {full }}=\left(P_{N L}^{\text {self } 100}+P_{N L}^{\text {cross } 100}\right) \times e^{\alpha\left(100[k m]-L_{\text {span }}[k m]\right)} \\
P_{N L}^{\text {self } 100}=\eta_{0}^{\text {self }}\left(1-e^{-0.3-\left|\frac{\left.\left.D^{\text {in }}+295-6.3 \times Z_{\text {peak }}+0.51 \times Z_{\text {peak }}\right)^{2}\right)^{1.5}}{3.5 \times\left(-295+6.3 \times Z_{\text {peak }}-0.51 \times Z_{\text {peak }}\right)^{2}}\right|^{1.5}}\right) \times\left(0.23 Z_{\text {peak }}+1\right) \times\left(P_{\text {peak }}^{\text {main }}\right)^{3} \\
P_{N L}^{\text {cross } 100}=1.8 \times \eta_{0}^{\text {cross }}\left(\frac{50[G H z]}{\Delta f}\right)^{2} \times \sum_{n_{\text {ch }}=1 . . . \frac{N_{c h}}{2}}\left\{\frac{P_{\text {peak }}^{\text {main }} \times\left(P_{\text {peak }}^{n_{\text {ch }}}\right)^{2}}{\left(n_{c h}\right)^{2}}\right\},
\end{gathered}
$$

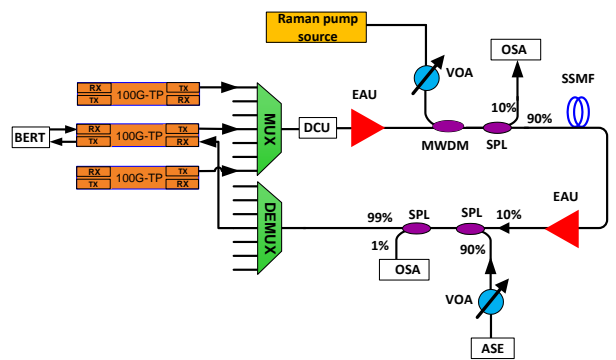

Рис. 1 Схема экспериментальной установки

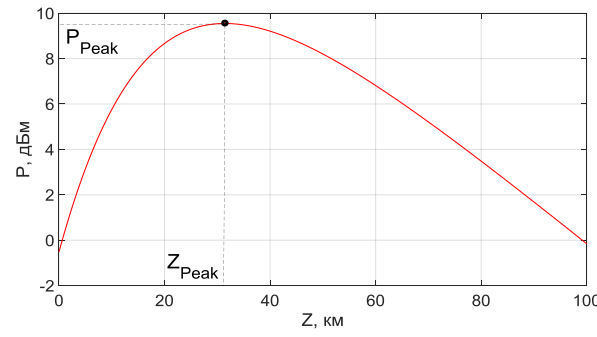

Рис. 2 Продольное распределение сигнальной мощности в ВОЛС с попутной рамановской накачкой

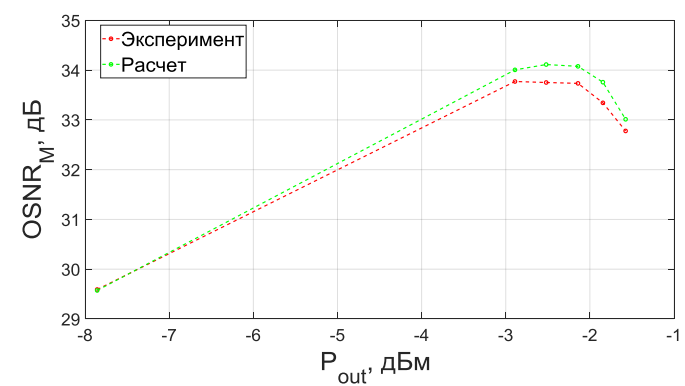

Рис. 3 Зависимость запаса по OSNR 31-го ITU-канала от выходной мощности в ВОЛС с попутной рамановской накачкой мощностью 29 дБм и с 8-ю симметрично расположенными воздействующими каналами с частотным интервалом 50 ГГц

\section{Литература}

[1] V. Gainov et al., Opt. Express, vol. 22, no. 19, p. 22308 (2014)

[2] D. Chang et al., J. Lightwave Technology, vol. 33, no. 3, pp. 631-638 (2015)

[3] S. J. Savory, Quantum Electron., vol. 16, no. 5, pp. 1164-1179 (2010)

[4] P. Poggiolini, J. Lightwave Technology, vol. 30, no. 24. pp. 3857-3879 (2012)

[5] Н. В. Гуркин et al., Quantum Electron., pp. 550-553 (2013)

[6] G. Agrawal, Elsevier, New York, p. 467 (2001) 